\title{
The ISS Water Processor Catalytic Reactor as a Post Processor for Advanced Water Reclamation Systems 07ICES-39
}

\author{
Tim Nalette, Doug Snowdon \\ Hamilton Sundstrand \\ Karen Pickering, Michael Callahan \\ NASA
}

\begin{abstract}
Advanced water processors being developed for NASA's Exploration Initiative rely on phase change technologies and/or biological processes as the primary means of water reclamation. As a result of the phase change, volatile compounds will also be transported into the distillate product stream. The catalytic reactor assembly used in the International Space Station (ISS) water processor assembly, referred to as Volatile Removal Assembly (VRA), has demonstrated high efficiency oxidation of many of these volatile contaminants, such as low molecular weight alcohols and acetic acid, and is considered a viable post treatment system for all advanced water processors. To support this investigation, two ersatz solutions were defined to be used for further evaluation of the VRA. The first solution was developed as part of an internal research and development project at Hamilton Sundstrand (HS) and is based primarily on ISS experience related to the development of the VRA. The second ersatz solution was defined by NASA in support of a study contract to Hamilton Sundstrand to evaluate the VRA as a potential post processor for the Cascade Distillation system being developed by Honeywell. This second ersatz solution contains several low molecular weight alcohols, organic acids, and several inorganic species. A range of residence times, oxygen concentrations and operating temperatures have been studied with both ersatz solutions to provide addition performance capability of the VRA catalyst.
\end{abstract}

\section{Introduction}

The ISS Water Processor Assembly (WPA) was designed to produce potable water from various waste streams including humidity condensate, waste hygiene and urine distillate. The initial chemical treatment process is carbon adsorption and ion exchange to remove organic and ionic containments in the waste stream. Low molecular weight organic compounds which are highly soluble in water, such as alcohols, are not effectively adsorbed and are oxidized to organic acids and carbon dioxide by the a catalytic reactor referred to as the WPA catalytic reactor or Volatile Removal Assembly (VRA).

Advanced water processors being developed for NASA's Exploration Initiative rely on phase change and/or biological processes as the primary means of water treatment. The phase change technologies include air evaporation, rotary vacuum distillation processes such as vapor compression distillation (VCD), wiped film rotating disc (WFRD) and cascade rotary distillation (CRD). Depending on the operating conditions of these 
processes, the distillate will contain low molecular weight volatile compounds; the exact volatile species and concentration depends on the operating temperature, feed stream, and method of pretreatment of each of the technologies. These low molecular compounds, similar to those found in the ISS waste water, must be treated in order to produce potable water. The general requirement for NASA potable water has been defined as having a total organic carbon (TOC) concentration of $0.5 \mathrm{ppm}$. The VRA is highly effective in oxidizing these compounds and is considered as a viable post treatment system for all advance water processors.

Previous investigations have presented information on the performance testing of the VRA with respect to nominal, and off-nominal, challenges associated with ISS waste water ${ }^{1}$. This paper presents the results of our on-going evaluation of the VRA, including performance testing of the VRA with respect to residence time, oxygen concentration and operating temperature using two additional ersatz solutions.

\section{Hamilton Sundstrand Developed Ersatz Solution}

The purpose of the ersatz solution for this test phase is to provide chemical challenges to the reactor that mimic the compounds present in the effluent of advance water processor and are simple to makeup. Many ersatz solutions have been used for performance testing of the VRA and new models have been proposed for transit activity. The various models are summarized below.

Four different ersatz solutions were used by NASA's Marshall Space Flight Center (MSFC) in evaluating the VRA reactor. ${ }^{1}$ The solutions are referred to as baseline alcohol, alcohol challenge, multi-component challenge, and modified alcohol challenge. With the exception of the multi-component challenge, the alcohol solutions were made from ethanol and 2-propanol. The multi-component challenge was made up from 13 compounds. Testing at MSFC demonstrated that the VRA had a 100\% margin on the oxidation of the nominal challenge, and a 50\% margin when subjected to the over challenge conditions. ${ }^{1}$

The original ISS Water processor specification has an organic load to the VRA reactor of approximately 29 ppm TOC composed mainly of ethanol, propylene glycol, acetone and 2-propanol. Due to changes in the ISS water Processor interface, the organic load to the catalytic reactor has been increased to about $65 \mathrm{ppm}$ TOC with 2-propanol comprising about $3 \%$ of the load and is referred to as the Modified Waste Water Model.

The transit model ${ }^{2}$ has a volatile TOC load of $109 \mathrm{ppm}$. Most of the TOC (55\%) is from ethanol. The remaining TOC consists of formic acid (19\%), propylene glycol (15\%), 2propanol (2\%) and acetone (1\%). Table 1 summarizes the various ersatz solutions. 
Table1 - Summary of Ersatz Models

\begin{tabular}{|c|c|c|c|c|}
\hline \multirow[b]{2}{*}{ Data Source } & \multirow{2}{*}{$\begin{array}{c}\text { Organic Load to } \\
\text { Catalytic Reactor } \\
\text { TOC } \\
\text { (ppm) } \\
\end{array}$} & \multicolumn{3}{|c|}{ TOC } \\
\hline & & Ethanol & 2-Propanol & Other \\
\hline $\begin{array}{l}\text { Baseline } \\
\text { Alcohol }\end{array}$ & 33 & $62 \%$ & $38 \%$ & \\
\hline $\begin{array}{c}\text { Alcohol } \\
\text { Challenge }\end{array}$ & 67 & $62 \%$ & $38 \%$ & \\
\hline $\begin{array}{l}\text { Multicomponent } \\
\text { Challenge }\end{array}$ & 66 & $31 \%$ & $10 \%$ & $\begin{array}{c}\text { Contains methanol, } \\
\text { 1,2-propanediol, } \\
\text { formic acid and } \\
\text { small amount of } \\
\text { other organics }\end{array}$ \\
\hline $\begin{array}{l}\text { Modified } \\
\text { Alcohol } \\
\text { Challenge } \\
\end{array}$ & 64 & $97 \%$ & $3 \%$ & \\
\hline $\begin{array}{c}\text { ISS Water } \\
\text { Processor } \\
\text { Specification } \\
\end{array}$ & 29 & $46 \%$ & $6 \%$ & $\begin{array}{c}\text { Acetone }(10 \%) \\
\text { Propylene glycol } \\
(38 \%)\end{array}$ \\
\hline $\begin{array}{c}\text { Modified Waste } \\
\text { Water model }\end{array}$ & 65 & $97 \%$ & $3 \%$ & \\
\hline Transit Model & 109 & $55 \%$ & $2 \%$ & $\begin{array}{c}\text { Acetone }(1 \%) \\
\text { Formic acid (19\%) } \\
\text { Propylene glycol } \\
(15 \%)\end{array}$ \\
\hline
\end{tabular}

In addition to the ersatz solutions discussed above, Hamilton Sundstrand (HS) developed a solution to be used in our in-house development testing. The criteria for the HS ersatz is the solution must represent the chemical challenge, be easy to makeup, be chemically stable and use compounds readily analyzed by routine laboratory techniques.

Since ethanol and 2-propanol are present in all the ersatz solutions discussed above, they were selected for incorporation into the HS ersatz. Additionally, since is has been shown that 2-propanol is difficult to oxidize, due to an acetone intermediate, it was decided to make the HS ersatz "robust" in regards to the 2-propanol concentration. The ISS Water Processor Specification, the Modified Waste Water Model, and the Transit Model, are 
considered more representative for future applications and therefore were used to further define the ratio of ethanol to 2-propanol to be used in the HS ersatz. Since the 2-propanol concentration in the Modified Waste Water and Transit models was lower than the ISS Water Processor Specification, it was decided to use the ISS model to further define the HS ersatz. In the ISS model, the total TOC from ethanol, 2-propanol and acetone is approximately $17.6 \mathrm{ppm}$. Of this total, ethanol composes about $75 \%$ of the TOC and the balance is from 2-propanol and acetone. The HS ersatz defined as a result of this approach is presented in Table 2.

Table 2 - HS Selected Ersatz Solution

\begin{tabular}{|c|c|c|c|c|}
\hline \multirow{2}{*}{$\begin{array}{c}\text { Solution } \\
\text { TOC } \\
\text { (ppm) }\end{array}$} & \multicolumn{2}{|c|}{ Ethanol } & \multicolumn{2}{|c|}{ 2-propanol } \\
\hline & $\begin{array}{l}\text { TOC } \\
\text { (ppm) }\end{array}$ & $\begin{array}{l}\text { Conc. } \\
\text { (ppm) }\end{array}$ & $\begin{array}{c}\text { TOC } \\
(\mathrm{ppm})\end{array}$ & $\begin{array}{l}\text { Conc. } \\
\text { (ppm) }\end{array}$ \\
\hline 50 & 38 & 72 & 12 & 21 \\
\hline 100 & 75 & 144 & 25 & 42 \\
\hline 150 & 112 & 216 & 38 & 62 \\
\hline 200 & 150 & 288 & 50 & 83 \\
\hline
\end{tabular}

\section{JSC Developed Ersatz Solution}

As part of the NASA funded study to evaluate the VRA as a post processor to the Cascade Distillation system, JSC developed a model very similar to the one proposed by Verostko et al in "Ersatz Wastewater Formulations for Testing Water Recovery Systems" ${ }^{2}$. The resulting JSC model for organics is presented in Table 3 and the inorganic model is presented in Table 4.

Table 3 - JSC Selected CDS Organic Distillate Concentrate 1 (1 ml of Concentrate/Liter of DI Water $=15 \mathrm{mg} / \mathrm{ml} \mathrm{TOC)}$

\begin{tabular}{|l|l|c|c|}
\hline \multirow{2}{*}{$\#$} & \multicolumn{1}{|c|}{$\begin{array}{c}\text { Organic } \\
\text { Compound Ingredients }\end{array}$} & \multicolumn{2}{|c|}{ Amount* } \\
\cline { 3 - 4 } & \multicolumn{1}{|c|}{ ml/L } \\
\hline 1 & *Formic acid (96\%) & - & 10.24 \\
\hline 2 & Methyl alcohol (99.8\%) & - & 5.22 \\
\hline 3 & Acetic acid (99\%) & - & 4.43 \\
\hline 4 & Isobutyric acid (99\%) & - & 3.98 \\
\hline 5 & Ethyl alcohol (99.5\%) & - & 4.04 \\
\hline 6 & *Lactic acid (85\%) & - & 0 \\
\hline 7 & $\begin{array}{l}\text { 2-Butoxy-ethanol or (ethylene glycol } \\
\text { butyl ether) (99\%)** }\end{array}$ & - & 1.33 \\
\hline 8 & $\begin{array}{l}\text { 4-Hydroxy-4-methyl pentanone or } \\
\text { (diacetone acetone) (99\%) }\end{array}$ & 1.2 & - \\
\hline 9 & Phenol (99\%) & - & 0.33 \\
\hline 11 & Hexanoic acid or (caproic acid) (99.5\%) & - & 0.25 \\
\hline 10 & Acetone (99.5\%) & & \\
\hline
\end{tabular}




\begin{tabular}{|l|l|c|c|}
\hline 11 & Octanoic acid or (caprylic acid) (99\%) & - & 0.11 \\
\hline 12 & Benzaldehyde (98\%) & - & 0.13 \\
\hline 13 & Benzyl alcohol & - & 0.10 \\
\hline 14 & Ethoxyethanol (99\%)** & - & 0 \\
\hline 15 & N,N-Dimethylformamide & - & 0.11 \\
\hline 16 & Urea (99.5\%) & - \\
\hline 17 & Ethylene glycol & 1.9 \\
\hline *Purity for Formic acid, Lactic acid and Benzaldehyde were used for \\
determining the amounts of each to add to Concentrate 1. Purity of the other \\
chemicals is 99\% or better and so the purity is less significant on their final \\
concentrations in the final ersatz distillate formulation for these compounds. \\
$* *$ Deleted and replaced by ethylene glycol
\end{tabular}

Table 4 - CDS Inorganic Distillate Concentrate 2 (1000x) (1 ml of Concentrate/Liter of DI Water = $14 \mathrm{mg} / \mathrm{L}$ Inorganic Compound)

\begin{tabular}{|c|l|c|}
\hline$\#$ & \multicolumn{1}{|c|}{$\begin{array}{c}\text { Inorganic } \\
\text { Compound Ingredients }\end{array}$} & g/L \\
\hline 1 & Potassium Dihydrogen Phosphate & 1.4 \\
\hline 2 & Ammonium Sulfate & 5.50 \\
\hline 3 & Sodium Nitrate & 2.60 \\
\hline 4 & Sodium Chloride & 4.12 \\
\hline & Total Inorganic Ingredient & 14.0 \\
\hline
\end{tabular}

\section{Testing}

All of theVRA evaluation testing utilized the same subscale development reactor that was used in the VRA development activity for the ISS WPA. The reactor has a $3.5 \mathrm{~cm}$ diameter, is $18.1 \mathrm{~cm}$ in length and contains $180 \mathrm{~cm}^{3}$ of flight VRA catalyst. Performance evaluations, using both ersatz solutions, were initially conducted at the ISS WPA VRA nominal operating condition of 10 minute residence time, water flow rate of $18 \mathrm{~cm}^{3} / \mathrm{min}$, a reactor temperature of $265^{\circ} \mathrm{F}$, a reactor pressure of 65 psig and an oxygen flow rate equal to1.5 times stoichiometric requirements. Additional testing investigated the effects of varying residence time, oxygen flow, reactor temperature and total TOC load on reactor performance. A simplified schematic of the VRA test setup is presented in figure 1. 


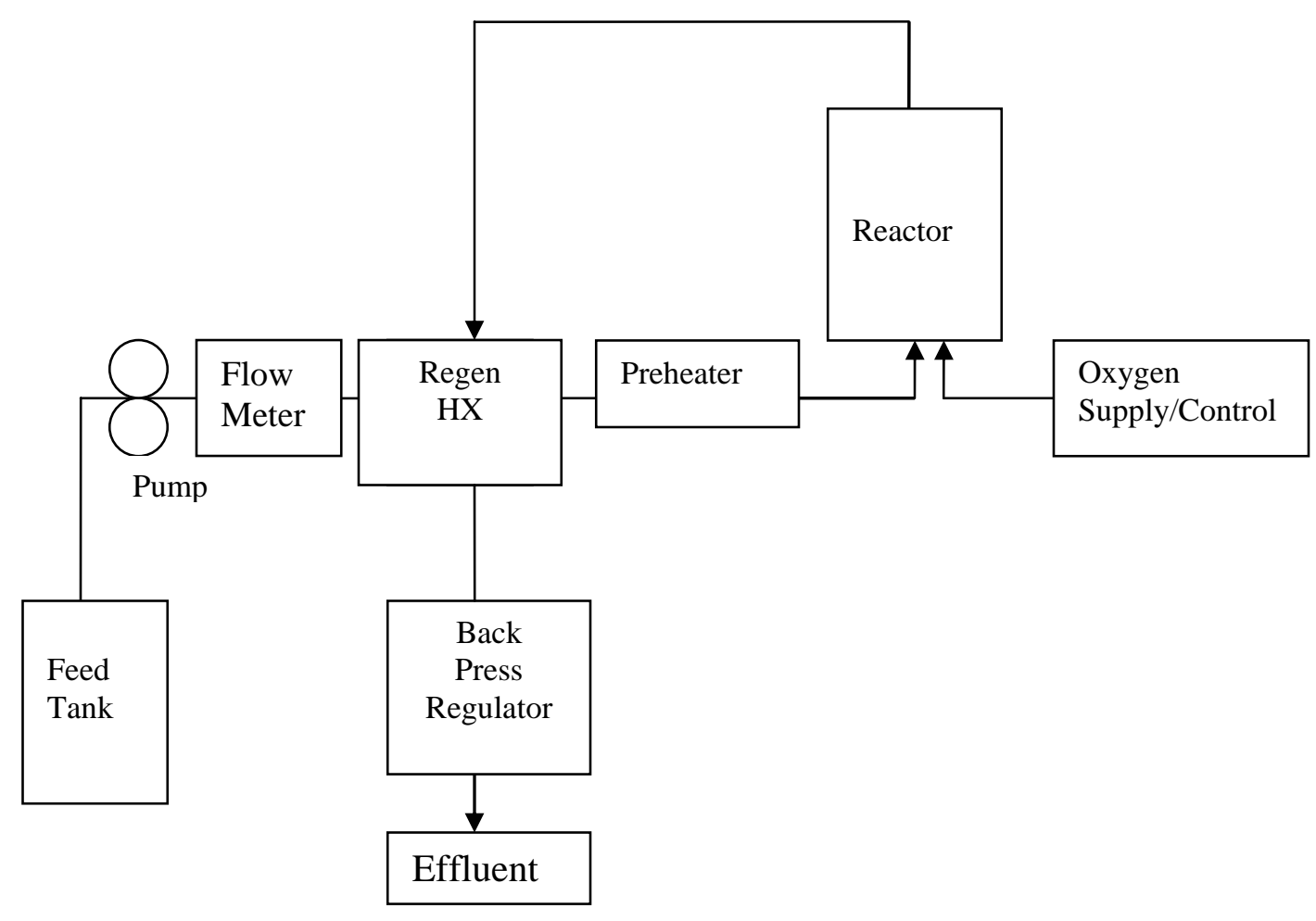

Figure 1 - Simplified Schematic of VRA Catalyst Evaluation Test Setup

Contaminates are mixed in a feed tank at the desired concentrations and this solution fed on a continuous basis to the reactor. The reactor is maintained at temperature by preheating the influent to the reactor and using a guard heater on the reactor to make up for heat loss. The oxygen flow rate is controlled using a mass flow controller, and the oxygen is injected directly into the inlet header of the reactor. The reactor pressure is regulated by a back pressure regulator to prevent boiling at the reactor operating conditions. Samples are obtained by collecting the effluent and analyzing for TOC, and when required, acetic acid and alcohols.

\section{HS Ersatz Testing}

The initial baseline performance evaluation operated the reactor at $265^{\circ} \mathrm{F}, 65 \mathrm{psig}$, and an oxygen flow rate equivalent to1.5 times the stoichiometric requirement. Testing was conducted to determine the residence time needed to produce an effluent with a TOC concentration of less than $0.5 \mathrm{ppm}$ when challenged with various feed concentrations of the HS ersatz. The effluent TOC of 0.5ppm was used as a reference since it was the ISS specification for maximum TOC in potable water. As indicated in Figure 2, for the range of inlet TOCs tested, when the inlet concentration is doubled, the required residence time to obtain $0.5 \mathrm{ppm}$ increases by approximately $50 \%$. Since the residence time is the catalyst bulk volume divided by the volumetric flow rate, this translates directly to required catalyst volume. 


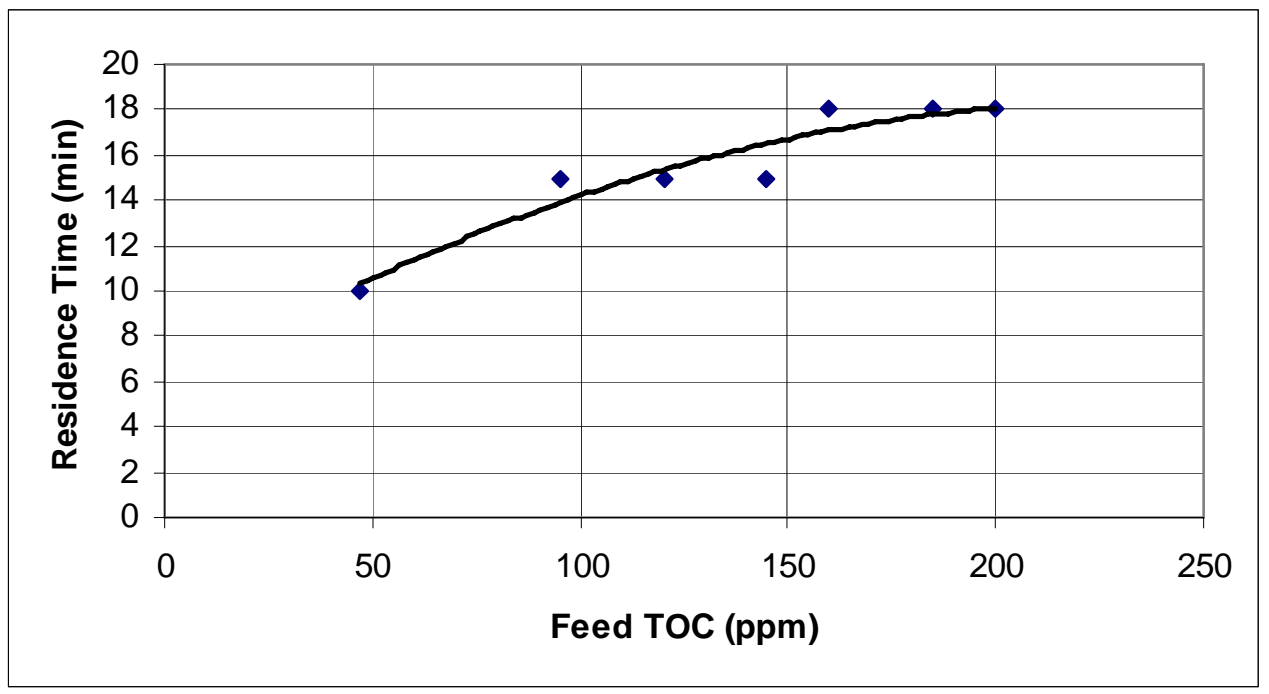

Figure 2 - Residence Time Required to Produce Effluent with TOC less than 0.5 ppm (HS Ersatz)

Figure 3 shows the effect of residence time on effluent quality at a fixed inlet of $200 \mathrm{ppm}$ TOC. At a residence time of 15 minutes, the effluent TOC is about $0.7 \mathrm{ppm}$ and at a residence times of 18 minutes the effluent TOC is approximately $0.4 \mathrm{ppm}$. This displays an approximate exponential behavior with the effluent TOC increasing by an order of magnitude for every $50 \%$ reduction in the residence time.

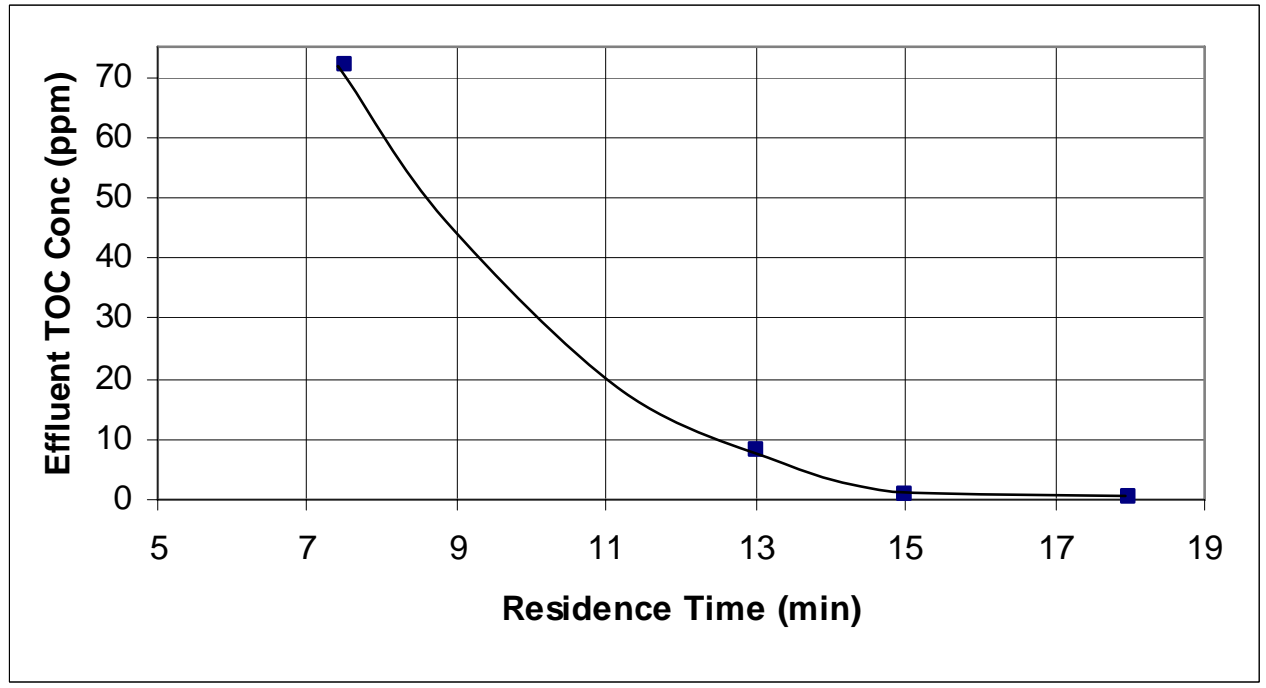

Figure 3 - Effect of Residence Time on Effluent TOC at Constant Inlet TOC of 200 ppm(HS Ersatz) 


\section{JSC Ersatz Testing}

The first set of tests using the previously define JSC ersatz solution challenged the reactor with an inlet concentration of 15 ppm TOC. At the baseline temperature, pressure and oxygen concentration discussed above, the effluent TOC was less than $0.2 \mathrm{ppm}$ for both 10 and 20 minute residence times. Due to time constraints, lower residence times have not been tested.

The nominal operating conditions for the VRA - a temperature of $265^{\circ} \mathrm{F}$ and a pressure of 65psig , required to prevent boiling at the reactor temperature- affect system design in the sense of requiring ancillary components to be designed to accommodate the elevated pressure operation. A lower operating temperature can therefore provide a potentially simplified, lighter, and lower power VRA. To evaluate this potential, the effect of reactor temperature on effluent water quality was determined for a nominal inlet TOC of $15 \mathrm{ppm}$ for temperatures ranging from $215-265^{\circ} \mathrm{F}$. The results of this test are presented in Figure 4, showing an approximate linear relationship of reactor temperature and effluent TOC concentration.

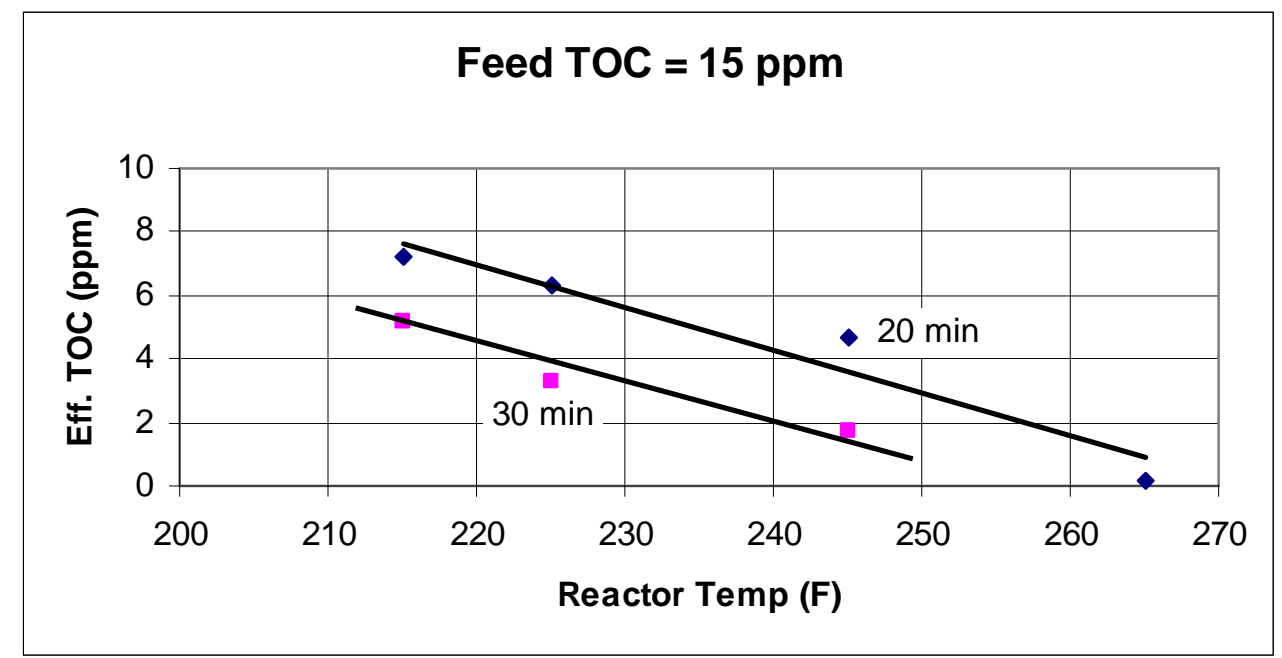

Figure 4 - Effect of Reactor Temperature on Effluent Water Quality (JSC Ersatz)

As seen in Figure 4, the effluent of the reactor exceeds $0.5 \mathrm{ppm}$ TOC for all temperatures less than $265^{\circ} \mathrm{F}$ even though the residence time was increased to 30 minutes. This may be indicative a minimum activation energy required, and shows that there is little margin relative to temperature control. The minimum operating temperature observed in this testing is consistent with previous test data obtained for the ISS flight WPA VRA.

While 15 ppm TOC is considered the nominal inlet contaminant load for the JSC ersatz, it was desired to evaluate the effect of higher concentrations that might result from a system upset. The first "over challenge” selected an inlet contaminant load of 100ppm using the JSC ersatz. The effect of residence time on effluent TOC is shown in figure 5. 


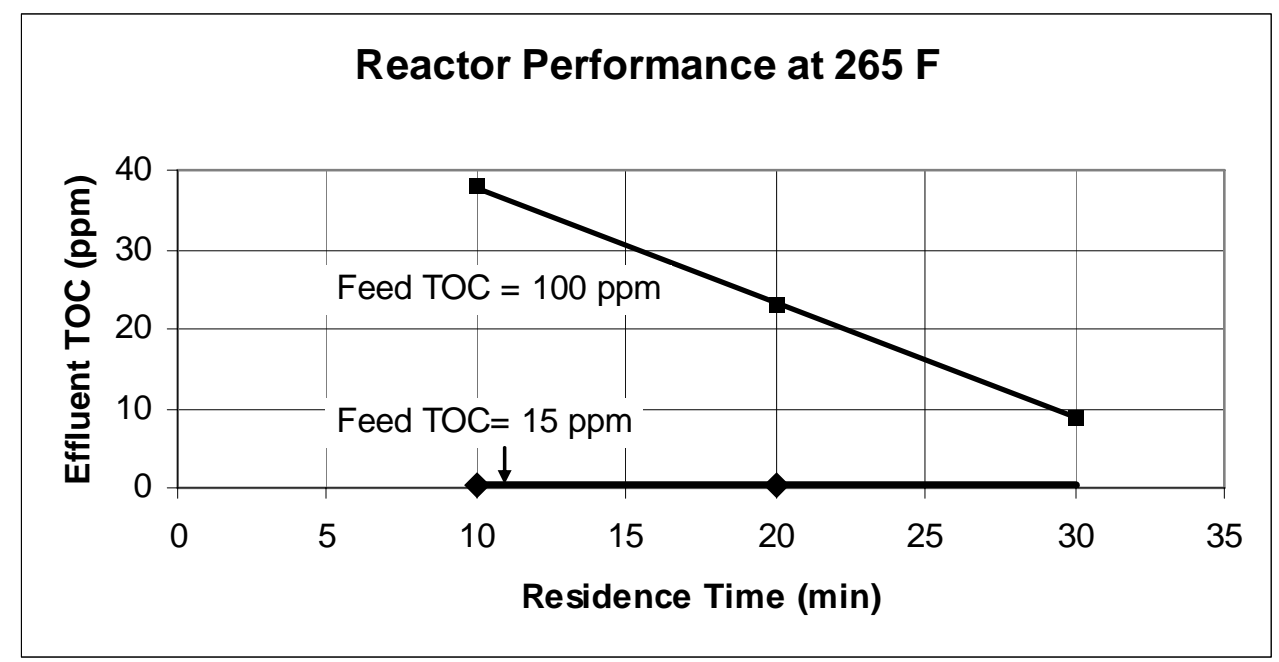

Figure 5 - Effect of Residence Time on Effluent Quality at 15 and 100 ppm Inlet TOC (JSC Ersatz)

The effluent exceeded 0.5 ppm TOC for all residence times tested when challenged with the 100 ppm JSC ersatz solution. While previous testing with other ersatz challenges had not specifically tested the VRA at such high "over challenge" conditions, testing conducted in support of the WPA had successfully produced water meeting the $0.5 \mathrm{ppm}$ TOC specification at contaminants loads approaching 2 times the nominal (25-30ppm TOC) specification. Future testing will be conducted to determine if increasing the reactor temperature will produce an effluent TOC of $0.5 \mathrm{ppm}$ or if oxygen mass transfer to the catalyst surface is limiting the reaction.

Figure 6 shows the effect of ersatz composition on reactor performance for 100 ppm JSC ersatz and 200 ppm HS ersatz. It is clear in this comparison that the JSC ersatz is more refractory as evidenced by the higher effluent TOC at residence times greater than 10 minutes. It is expected that these data would diverge further if equal concentrations were tested. These results point to the importance of developing a representative ersatz challenge and also the need to have adequate margin in the oxidation system design.

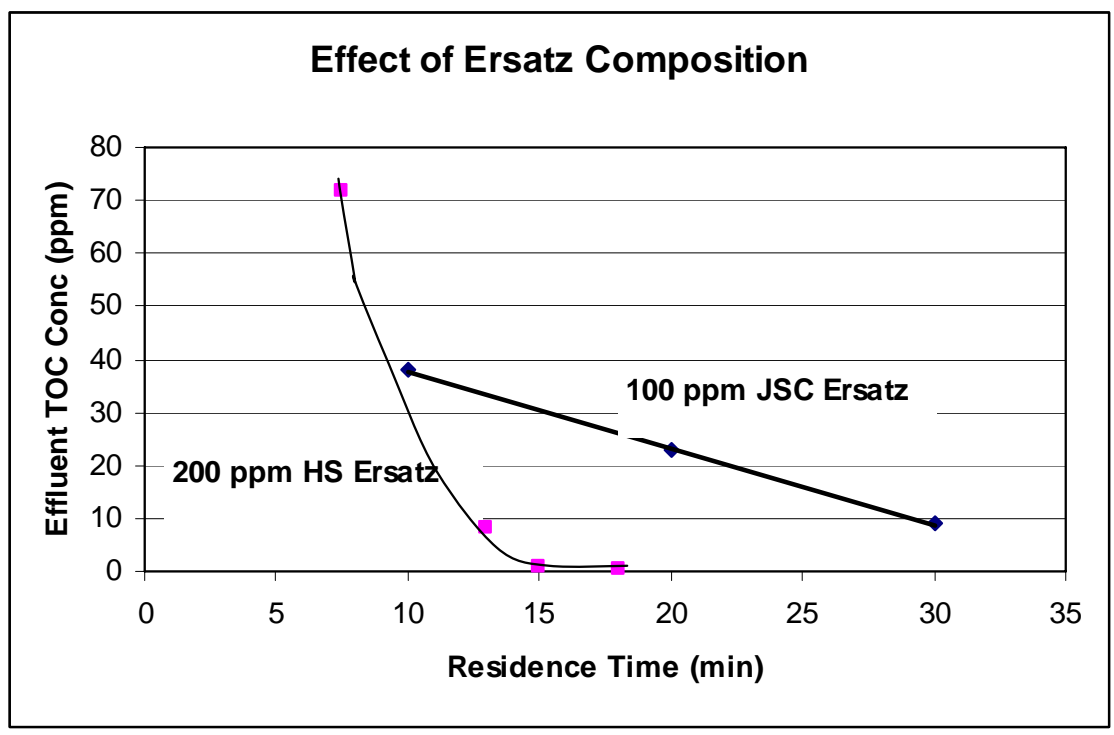


Figure 6 - Effect of Ersatz Composition on VRA Performance

\section{Conclusions}

Various ersatz solutions have been defined to represent contaminant challenges and product water constituents associated with advanced primary water processors being developed for differing NASA missions. The aqueous phase VRA oxidation technology has demonstrated efficient oxidation for a variety of representative ersatz solutions, in addition to being flight certified for the ISS WPA. Additional testing has been conducted using a JSC ersatz solution with a nominal inlet TOC concentration of $15 \mathrm{ppm}$, which is representative of the cascade distillation system being developed as an advanced water processor for exploration missions. Preliminary evaluations with this latest ersatz solution have demonstrated the VRA technology to be effective in producing product water which meets the nominal 0.5ppm TOC NASA potable water standard.

This latest round of testing, using two additional ersatz solutions, has reinforced the capability of the VRA technology operating at the nominal conditions previously defined for the ISS WPA. Testing has demonstrated that operation of the VRA oxidation reactor at $265^{\circ} \mathrm{F}$, a minimum residence time of 10 , and an oxygen concentrations of 1.5 times the stochiometric requirement is capable of producing potable water according to the nominal NASA standard with inlet TOC concentrations up to 2 times the nominal inlet concentration.

\section{Contact}

Tim Nalette , email at t.nalette@hs.utc.com

\section{References}

${ }^{1}$ Layne, D.L.; Tatara, J.; “Performance Assessment of ISS Water Processor Assembly Reactor”, International Conference on Environmental Systems, July 2002, 04ICES-17.

${ }^{2}$ Verosko, C.; Carrier, C.; Finger, B.; "Ersatz Wastewater Formulations for Testing Water Recovery Systems”, International Conference on Environmental Systems, July 2004, 2004-01-2448. 